\title{
Ouvidos para ler: contextualizando audiolivro, leitura e entretenimento ${ }^{1}$
}

\author{
Rafael de Oliveira BARBOSA ${ }^{2}$
}

\begin{abstract}
Resumo:
Este trabalho realiza uma breve contextualização histórica do audiolivro, influenciada pelos estudos da História da Leitura (CAVALlO; CHARTIER, 1998) e da Comunicação (BARBOSA, M., 2013). Abordam-se diversos casos em que literatura e fonografia foram mescladas na produção desse formato editorial, assim como destaca-se a presença de leituras oralizadas desde antes do fonógrafo. São combinadas a pesquisa documental virtual (em jornais, revistas etc.) e uma breve revisão bibliográfica referente aos audiolivros (RUBERY, 2011; 2016). Entre rupturas e continuidades, temos que o audiolivro se relaciona historicamente não apenas com os leitores cegos, mas também com o consumo de entretenimento dos videntes.
\end{abstract}

Palavras-chave:

Audiolivro. Fonografia. Leitura. Entretenimento. Comunicação.

\section{Ears to read: contextualizing audiobook, reading and entertainment}

Abstract:

This paper presents a brief historical contextualization of the audiobook through the History of Reading (CAVALLO; CHARTIER, 1998) and Communication (BARBOSA, M., 2013). Several examples in which literature and phonography were merged to produce this editorial product are given along this work, as well as it points to the presence of oral readings since before the phonograph appearance. A virtual documentary research (in newspapers, magazines etc.) and a literature review forms our methodology. With ruptures and continuities, audiobook historically relates not only itself to blind readers, but also to the entertainment of the non-blinds.

Keywords:

Audiobook. Reading. Phonography. Entertainment. Communication.

\section{Oídos para leer: contextualizando audiolibro, lectura y entretenimiento}

Resumen:

Este artículo presenta una breve contextualización histórica del audiolibro, influenciada por los estudios de la Historia de la Lectura (CAVALLO; CHARTIER, 1998) y de la Comunicación (BARBOSA, M., 2013). Se abordan diversos casos en los que la literatura y la fonografía se mezclaron en la producción de ese formato editorial, así como se destaca la presencia de lecturas oralizadas ya antes del fonógrafo. Combinamos una investigación documental virtual (en periódicos, revistas etc.) con una breve revisión bibliográfica sobre audiolibros (RUBERY, 2011; 2016). Entre rupturas y continuidades, observamos que el audiolibro se relaciona históricamente no solo con los lectores ciegos, sino también con el consumo de entretenimiento de los videntes.

Palabras clave: Audiolibros. Lectura. Fonografia. Entretenimiento. Comunicación.

\section{INTRODUÇÃO}

\footnotetext{
${ }^{1}$ Uma primeira versão deste artigo foi apresentada no GT de História da Mídia Sonora do $3^{\circ}$ Encontro Regional Sudeste de História da Mídia, na Universidade Federal do Rio de Janeiro, de 14 a 15 de abril de 2014.

${ }^{2}$ Doutorando do Programa de Pós-Graduação em Comunicação na Universidade do Estado do Rio de Janeiro, na linha de Tecnologias de Comunicação e Cultura. Bolsista Faperj. E-mail: rafaobarbosa@ hotmail.com.
} 
A investigação sobre audiolivros comerciais produzidos para videntes nos colocou como possibilidade, e também necessidade, o desenvolvimento de uma contextualização sobre esse formato editorial e as práticas dos seus leitores, com vistas a verificar em que medida a leitura com os ouvidos e a concepção de um audiolivro têm panos de fundo históricos mais longos.

O que se segue é, portanto, uma busca por um entendimento histórico sobre as transformações do audiolivro como produto de entretenimento, junto a mutações nas tecnologias fonográficas, também para pessoas sem cegueira. O objetivo é contribuir para relativizar a associação direta do uso do formato sonoro aos deficientes visuais ${ }^{3}$, importantes na consolidação da legitimidade dessa forma de leitura (RUBERY, 2016), e destacar o consumo dos não-cegos, o que trará à discussão a própria relação entre livro sonoro e livro impresso e seus espaços no conjunto das práticas de leituras dos consumidores.

Para tanto, discutimos um pouco mais neste estudo o uso de fonógrafos, gramofones, cilindros, discos e outros dispositivos de áudio nas práticas de leitura com o ouvido. Tal abordagem permite abarcar as modificações materiais nos suportes textuais (nesse caso, de armazenamento, processamento e reprodução do audiolivro), para pensá-los como condicionantes nas práticas de leitura e não repositórios de textos.

Apresenta-se, assim, uma visão sobre as leituras com o ouvido não como subpráticas, mas como atividades presentes - e em muitas situações, concomitantes e mais comuns que a leitura silenciosa - há mais tempo do que se costuma destacar. Dispondo de alguns poucos trabalhos e artigos acadêmicos voltados especificamente ao audiolivro, esta tentativa de contextualização viabilizou-se principalmente por meio de documentos históricos em fontes na internet, no acesso a acervos de instituições, como o Arquivo Público do Estado de São Paulo, e bibliotecas virtuais. Entre fontes primárias e secundárias, deparamo-nos com discografias, catálogos, vídeos, correspondências e artigos, notícias e propagandas de jornais e revistas, além de outras referências textuais da transição do século XIX para o século XX e de décadas posteriores.

\footnotetext{
${ }^{3}$ Tal passo é resultante também de um breve estudo de caso que realizamos sobre a American Foundation for the Blind (AFB) (BARBOSA, R., 2013), instituição que, no início do século XX, incentivou a produção de talking books para deficientes visuais civis e soldados feridos em guerra, a fim de lhes garantir acesso à literatura.
} 


\section{Leitura com o ouvido e fonografia}

Para entender a relação audiolivro/entretenimento, observamos a articulação entre a história da chamada Leitura Ouvida e o surgimento da tecnologia fonográfica, fator importante que possibilitou a materialização do livro falado como formato editorial.

Observamos que, durante longo período, ouviam-se e narravam-se histórias, romances, contos, poesias e diversos outros gêneros textuais, muito em função da necessidade de transmissão cultural - de costumes, técnicas, leis, enfim, conhecimento - e de diversão, passatempo, em sociedades com os mais diferentes níveis de alfabetização. O pesquisador sueco Jesper Svenbro aponta, por exemplo, a presença de leitura silenciosa no mundo grego antigo como prática de limitados grupos de leitores e desconhecida da maioria dos indivíduos, principalmente analfabetos. "[...] Para o leitor que lê pouco e de maneira esporádica, a decifração lenta e hesitante do escrito não conseguiria fazer surgir a necessidade de uma interiorização da voz, pois a voz é exatamente o instrumento pelo qual a sequência gráfica é reconhecida como linguagem" (SVENBRO, 1998, p. 55).

No mundo romano, entre os séculos II e III d.C., explica Gugliemo Cavallo (1998), diversas fontes iconográficas e literárias apresentam um cenário variado de modalidades de leitura. Entretanto, prevalecia a leitura em voz alta, muitas vezes acompanhada de certa gestualidade, até diante de um público ouvinte. Por meio de registros da época, o estudioso evidencia a própria relação entre escrita literária e oralidade. Diz Cavallo (1998):

A leitura podia ser pessoal ou também feita por um leitor que assegurava a mediação entre o livro, o ouvinte ou ainda todo um auditório. No caso de certas composições poéticas, várias vozes leitoras se alternavam, segundo a estrutura do texto. Esse recurso à oralidade explica também a forte interação existente entre escrita literária e leitura. A primeira era dominada pela retórica que impunha suas categorias às outras formas literárias, poesia, historiografia, tratados filosóficos e científicos; por isso, ela exigia, sobretudo diante de grandes auditórios, uma leitura expressiva, modulada por tons e cadências de voz conforme o gênero do texto e os pretendidos efeitos de estilo. Não por acaso, o verbo que indica a leitura da poesia é frequentemente cantare, e canora o termo que designa a voz do intérprete. Ler um texto literário era, em suma, quase executar uma partitura musical. (CAVALLO, 1998, p. 80, grifo nosso). 
Essa inter-relação entre escrito e voz, explica o autor, requeria forte presença de um estilo oral na própria composição textual. O texto devia ser produzido visando a pronunciação, para o que auxiliavam os sinais críticos e a própria pontuação, “[...] funcionais não tanto para o andamento lógico, mas antes para a estruturação 'retórica' do escrito, com a finalidade de assinalar pausas de respiração e de ritmo para a leitura em voz alta [...]" (CAVALLO, 1998, p. 82), ainda que sem nenhuma padronização ou sistematização de seu uso. O próprio lançamento de um texto literário era feito pelo recitatio, a leitura pública diante de um público ouvinte.

Na Alta Idade Média, com uma nova atitude diante da escrita, a oralização do escrito assume um estatuto um pouco diferente, com o deslocamento da leitura em voz alta para a liturgia, uma prática mais monástica ligada ao ensino religioso (PARKES, 1998). A escrita era percebida como mais que representação da fala, explica Malcom Parkes ao citar Isidoro de Sevilha - que no século VII já via as letras com poder de trazer a fala dos ausentes de forma silenciosa. "As letras em si mesmas eram sinais de coisas. E a escrita passa a ser, daí em diante, uma linguagem visível capaz de transmitir algo de forma direta para a mente por intermédio do olho" (PARKES, 1998, p. 106). Mudanças na produção textual e a presença maior de textos vão influenciar também no crescimento da chamada leitura escolástica, com uma postura mais dedicada ao comentário e explicação dos textos. Além disso, com mais textos à disposição, será preciso ler mais e mais rápido. Jaqueline Hamesse (1998) retrata a substituição da audição pela abordagem visual, mais fragmentária e utilitária.

Apesar do crescimento da forma silenciosa de leitura, o cenário com predominância e importância da oralidade teria tardado em se modificar, mesmo após o advento da prensa de Gutenberg. Em A Letra e a Voz: A Literatura Medieval, Zumthor apresenta a função de "cantores, recitadores, atores e leitores públicos aos quais a sociedade medieval confiou a transmissão e a 'publicação' de sua poesia” (ZUMTHOR, 1993, p. 55). E mesmo com a presença da escrita e após o advento da prensa, o poder da voz continuaria durante algum tempo a se expressar dentro da família, na produção de bens, na religião, no direito, no ensino e na arte. Ademais, devido às condições materiais da escrita e às imposições físicas desta ao leitor, a ideia de leitura estava ligada a uma certa ruminação, pois, no contato com o texto, "apenas a articulação vocal permitia resolvê-lo na prática (ZUMTHOR, 1993, p. 105).

Em suma, o medievalista aponta para uma convivência e colaboração entre 
oralidade e escrita (manuscrito e impresso), em que a primeira ainda teria predominância alguns séculos depois do aparecimento da prensa, até a massificação da escritura, no século XIX. "No início do século XVI, nem o suporte impresso do livro ainda se tinha verdadeiramente imposto na prática, nem o conteúdo das mensagens se tinha verdadeiramente liberado de uma herança cultural de séculos dedicados às transmissões vocais [...]” (ZUMTHOR, 1993, p. 111).

Em "História da Comunicação no Brasil”, Marialva Barbosa (2013) também nos apresenta a intensa oralidade como cenário do país no século XIX, época em que a nação começa a entrar em contato mais frequentemente com a imprensa e com os novos meios de comunicação, como a fotografia, o cinematógrafo e a fonografia. Em seu trabalho, a autora teoriza sobre uma sociedade em que, mesmo com o advento de tecnologias, conviviam e se atravessavam os mundos letrado e oral, inclusive nas práticas de escrita e leitura. Na análise desse contexto culturalmente plural, por meio de jornais e documentos como indícios históricos, Marialva Barbosa (2013) discorre sobre as habilidades de leitura e escriturária de alguns escravos, sua inserção entre os letrados, e as práticas comuns de leitura em voz alta e coletiva, como na cena editada da Revista Ilustrada em que onze escravos liam coletivamente um discurso abolicionista no jornal O Paiz, com um deles ao centro vocalizando o texto enquanto os demais, "podemos supor, fazem o mais absoluto silêncio. Escutam com atenção as palavras que do mundo impresso invadem o mundo oral" (BARBOSA, M., 2013, p. 149).

Tal mistura de formas de leitura seguiu no século XX, com a "distribuição oral" dos jornais em ambientes privados, entre amigos e familiares e no trabalho, para o que podem ter contribuído os baixos índices de alfabetização da época. "O texto transmitido pelos periódicos era, assim, também discurso falado, cuja força da locução e da compreensão dependia dos aspectos articulados do discurso, mas também da mímica, dos gestos, ou seja, dos elementos não articulados" (BARBOSA, M., 2013, p. 205). Além disso, a integração entre oralidade e escrita se dava, muitas vezes, na produção de textos escritos, em cartas, poesias e periódicos, marcados por características estruturais e de linguagem do texto oral para representar diálogo, conversas, falas e entonações, tornando presente o autor ausente.

Ao considerarmos esse caminho de misturas entre escrita e oralidade, a realização de produções sonoras baseadas em obras literárias como modo de entretenimento, possível com o surgimento do fonógrafo no século XIX, não nos parece 
um movimento de ruptura em relação ao contexto cultural vigente, mas variação ou transformação de um conjunto de práticas de leitura historicamente presentes.

Um aspecto primeiro de diferenciação do audiolivro é que, por meio das tecnologias de captura e reprodução do som, desfez-se a necessidade da presença física do intérprete (ou ledor) para se ouvir uma história. O som, agora estável e recuperável, pôde ser percebido fora de seu contexto de produção, como a palavra escrita, apropriada pelo leitor em momento diferente da enunciação (escrita) por parte do autor. Com isso, podemos, por um lado, reconhecer a continuidade da oralização da literatura e, por outro, começar a pensar a escuta de audiolivros como uma outra experiência de leitura, inclusive na perspectiva estética (HAVE; PEDERSEN, 2016) em função de diferentes condições materiais da leitura.

Nesse sentido é que a invenção do fonógrafo por Thomas A. Edison (1878), no final do século XIX, pode ser tratada como marco importante dentro da leitura ouvida: há um paralelismo entre as transformações no campo da fonografia e a idealização de um produto editorial em formato sonoro.

\section{Fonografia e audiolivro}

Para apresentar os audiolivros concebidos inicialmente tanto para deficientes visuais quanto para leitores não-cegos, é possível indicar alguns tipos de registros sonoros de estúdios americanos, feitos a partir do início do século XX, incluindo-se as adaptações para o áudio de pequenos trechos de obras literárias, seja por meio de uma simples recitação ou do uso de um tom mais cantado por parte dos intérpretes (CAMLOT, 2011; RUBERY, 2014).

No início do século XX, inclusive, algumas gravações de estúdios americanos parecem já ter chegado ao Brasil, por exemplo, pela Casa Edison, dos irmãos Fred e Gustavo Figner, atuantes no segmento fonográfico. Em alguns anúncios das revistas produzidas pela loja, observa-se a exclusividade, por exemplo, do agente Columbia Phonograph Company, de Nova York, no Brasil (O ECHO, maio 1908).

Na releitura de edições da revista Echo Phonográphico, publicação mensal lançada em 1902 pelos irmãos Figner como um "jornal explicativo da arte fonográfica" (PALMA, 2011, p. 253), encontram-se indícios de penetração e incentivo à tecnologia fonográfica em território nacional. Tal publicação informava, por meio de manuais, conteúdos técnicos detalhados sobre funcionamento de agulhas, cilindros e discos. 
Realizava recomendações técnicas para uso mais eficaz dos aparelhos; e incentivava gravações caseiras (ECHO PHONOGRAPHICO, set. 1902). E, principalmente, a publicação apresentava as múltiplas aplicações da recente tecnologia inventada por Edison, como aparece na seção “O X da Phonographia”, na edição de outubro de 1902.

Nos grandes salões, ao lado do piano, que desprende melodias sonoras, arrebatadas das suas teclas por mãos de fada (as esposas queridas e as noivas adoradas) ostenta-se em pedestal artístico o Graphophone modelo, que não raro imprime nos cylindros uma canção de amor, uma poesia inspirada, um romance em poucos capítulos!!

A voz timbrada de um cantor, qualquer que elle seja, tenor ou barytono; a voz argentea e pura de um soprano ou contralto, ficarão gravadas, para sempre, no tubo do aparelho, e, quão agradavel não é, ahi a momentos, ouvir-se a reprodução límpida, correcta das mesmas canções de amor, das mesmas poesias e dos mesmos romances! (O X..., out. 1902, p. 2).

Devem ser destacados no catálogo da Casa Edison gêneros que vão de discursos a poesias e romances curtos, ainda que não fossem predominantes. Outro exemplo pertinente, também relacionado ao consumo doméstico da fonografia, encontra-se na primeira página da edição de setembro do mesmo ano. Sob o título "Monologos e poesias", anunciam ao leitor:

\section{- Quereis rir e folgar?}

Procurai, na Casa Edison, os cylindros especiaes contendo jocosos monólogos, em prosa e verso, declamados por artistas cômicos de primeira linha.

- Quereis forçar a hilaridade?

Reuni, em vosso repertório, meia dúzia desses tubos, impressos com interessantes versos de um espirito fino e inoffensivo, e divertireis os vossos convidados e amigos.

Vide os novos Catálogos da Casa Edison, cuja distribuição continua a ser gratuita. (MONOLOGOS..., set. 1902, p. 1).

Assim, as fontes documentais parecem sugerir a existência, ainda que mínima, de leituras gravadas no Brasil no início do século XX para fins de entretenimento. Tais discos ainda não serão tratados aqui como audiolivros. Não apenas por conta da pouca capacidade de armazenamento dos cilindros e discos da época, mas também devido ao imprescindível mergulho investigativo em discografias e catálogos para confirmar possíveis gravações literárias dentro dessa "categoria".

Por outro lado, as informações coletadas indicam a existência de recitações, 
romances, poesias e outros textos escritos experimentados em formato fonográfico, criando uma ponte entre tais arquivos e o passado recente (a ideia "livro fonográfico", de Thomas Edison) e o que viria em seguida (o livro falado, o audiolivro). Nesse sentido, sugere-se um processo contínuo de reconfiguração da leitura com o ouvido e da literatura sonora que expõe essa copresença entre as funções de diversão e acessibilidade. Ressalvamos, porém, que tais fontes históricas funcionam como indícios de ideias circulantes em sua respectiva época em torno da tecnologia sonora, não sendo "fontes da verdade", já que são, principalmente, publicações com fins comerciais, publicitários.

Nos acervos digitais de dois importantes jornais brasileiros, O Globo e O Estado de S. Paulo, pouco foi encontrado também acerca das práticas de leitura com audiolivros e sobre o próprio formato. Apenas a partir da década de 80 algumas poucas reportagens ou notas foram publicadas, sendo insuficientes ao nosso objetivo inicial de identificar mais momentos da existência do livro sonoro no país.

Todavia, destacam-se alguns casos de produção de audiolivros para entretenimento, como o do Selo Festa, criado nos anos 50 pelo jornalista Irineu Garcia e que durou até o início da década de 70. Conforme apresenta a reportagem "Coleção traz à tona raridades do selo Festa", publicada no site da Folha de S. Paulo em 24 de fevereiro de 2005, no catálogo do Selo Festa estão músicas; registros sonoros de obras literárias (romances e poesias), como uma adaptação de "O pequeno príncipe", de Antoine de Saint-Exupery, interpretada pelo grupo de teatro Paulo Autran [1950], com música de Tom Jobim; os textos de Pablo Neruda, em "XX Poemas de amor e uma canção desesperada"; e os poemas de Federico Garcia Lorca, em "Poemas e Canções", ambos em espanhol. Entre os nomes da literatura brasileira lançados pelo Selo Festa, está o poeta João Cabral de Melo Neto, que narra seus próprios textos.

A partir de 1960, a gravadora Continental, de São Paulo, levaria até às crianças clássicos da literatura infantil mundial e contos brasileiros, com a "Coleção Disquinho". Sob a direção do compositor Carlos Alberto Ferreira Braga, o Braguinha (ou João de Barro), a companhia lançou discos compactos (e coloridos) com histórias musicadas, com narração de Sônia Barreto, Nelly Martins e outros - e que também compunham histórias - e personagens interpretados pelo elenco do Teatro Disquinho. Até o final dos anos 80, foram cerca de 70 discos, incluindo títulos como "Estória da dona Baratinha" (1960), “As aventuras do Saci Pererê" (1970), "Aladim e a Lâmpada maravilhosa" 
(1983), entre outros.

Em 1977, o jornalista Aramis Millarch destacaria diversas vezes em sua coluna no jornal Estado do Paraná o trabalho desenvolvido pela editora Continental. Em 13 de novembro, citou o acervo de discos infantis (segundo ele, 20 LPs, cada um contendo de duas a quatro histórias, e também em compactos duplos) feitos pelo estúdio, e lembrou o cuidado dedicado à produção dessas narrações, que incluíam importantes nomes da música e do rádio brasileiros, como Radamés Gnatalli, Paulo Tapajós e João de Barro (DISCOS, s.d.). Escreveu Millarch sobre a Continental: “uma das poucas gravadoras realmente preocupadas com o público infantil, em termos de gravações. [...] Produzidos há 10, 15 ou até 20 anos, as gravações infantis da Continental continuam a encantar as crianças, pois foram realizadas com extrema competência" (DISCOS, s. d.).

Ainda na década de 60, mais especificamente entre 1965 e 1966, além das radionovelas, o rádio brasileiro também foi espaço para recitações de curtas obras literárias, como o quadro "Cinco minutos com Paulo Autran", na Rádio Eldorado AM, de São Paulo, em que o ator interpretava trecho de poemas como "Receita de Mulher", de Vinicius de Moraes; trecho da peça "Otelo", de William Shakespeare; além de poemas e crônicas de Carlos Drummond de Andrade. Duas décadas depois, produziu-se uma coletânea de algumas dessas interpretações em LP. ${ }^{4}$

Já nas décadas de 80 e 90, as obras em áudio também chegaram ao público brasileiro como produto de entretenimento por gravadoras e editoras como Polygram (ZÓZIMO... set 1993, p. 3), Livraria da Vila (LIVROS... 1994, p. D3) e Sony. A própria Academia Brasileira de Letras já lançou audiolivros, como o que incluía textos do já mencionado João Cabral de Melo Neto narrados por Marly de Oliveira, sua mulher (PESSOAS... jun. 1994, p. 14).

Curiosamente, é preciso ressaltar como a retórica dos jornais em torno dos audiolivros no Brasil foi bastante semelhante, nas mais diversas décadas. As manchetes e matérias evidenciavam, e ainda evidenciam, o caráter da novidade - o que sugere a dificuldade que o produto tem enfrentado para se popularizar no país - e da mobilidade dos audiolivros.

Como exemplos temos a reportagem do Caderno 2, do jornal O Estado de $S$. Paulo, de 2 de junho de 1994, com o título "Livros falados chegam ao mercado". Nela,

\footnotetext{
${ }^{4} \mathrm{O}$ lista de poesias contidas no LP pode ser consultada no seguinte link: <www.discogs.com/PauloAutran-Paulo-Autran/release/6002848>. As gravações originais das interpretações de Paulo Autran em seu programa na Rádio Eldorado já não estão mais disponíveis no site do Instituto Moreira Salles.
} 
o audiolivro é definido como "uma fita cassete, com duração de 40 a 80 minutos, em que o próprio autor é o narrador. O produto é novidade no Brasil, mas já tem mercado estabelecido na Europa e nos Estados Unidos - neste último, em seis anos rendeu US\$ 6 bilhões”. No Segundo Caderno, de $O$ Globo, em 18 de junho do mesmo ano, sob o título “"Diário de um mago' vira audiolivro de quatro horas”, em referência à adaptação da obra de Paulo Coelho, o mercado para o formato em áudio é tido como "promissor, a julgar pelos lançamentos sucessivos". Na Revista O Globo, de 30 de outubro de 2005, um site francês especializado para download de audiolivros chega ao Brasil destacado sob o título "A vez do audiolivro". Os criadores da página já evidenciam como o avanço tecnológico chegara aos livros falados. "É possível ouvir num computador, gravar num CD para usar no carro ou num discman. Também dá para tocar em MP3 players e outros aparelhos portáteis", diz Frédéric Bonnet (A VEZ... out. 2005, p. 41).

Por fim, verifica-se, tanto por meio das referências bibliográficas quanto pelas diversas produções de obras sonoras citadas, a longa presença da "literatura sonora" no conjunto das práticas de leitura dos videntes, desde Thomas Edison. Assim, nossa investigação busca nuançar a imediata associação entre audiolivros e seu uso por cegos. A partir de outras referências, podemos ainda constatar a importância da audioleitura e da produção de audiolivros na descentralização nas concepções de livro e leitura do objeto impresso. Afinal, escreve Matthew Rubery (2016), pesquisador que se debruça sobre os audiolivros,

[...] assim como a prensa liberou o livro da dependência do escriba, o fonógrafo representou uma libertação análoga de sua dependência do impresso. Se tal otimismo com relação à evolução dos livros deixa muitos leitores desconfortáveis hoje, em um momento em que a longevidade do livro impresso está novamente em dúvida, é porque em parte nós nos acostumamos a associar impresso com progresso e não sabemos como responder aos desafios colocados pelos novos meios. (RUBERY, 2016, p. 54, tradução nossa).

\section{Tecnologia sonora e literatura}

Vêm de longe as expectativas e as representações criadas em torno do encontro literatura-fonografia, que, de certa forma, levaram a certas experiências empreendidas no campo literário desde então.

$\mathrm{O}$ artigo The book of the future: or whispering machines. A speculation, publicado em 24 de junho de 1885 no jornal australiano The Mercury, mostra que as 
novidades em torno da possibilidade de uma "literatura fonográfica" tinham cruzado o mundo sete anos após a invenção do fonógrafo. O periódico levanta questões e especulações sobre experimentos iniciais realizados para o desenvolvimento de um aparelho de reprodução de livros sonoros. No texto, por exemplo, abordam-se temas como portabilidade, novas possibilidades de leitura, o uso dos sentidos (olho/ouvido), a concentração na leitura e a substituição da voz humana pela de um autômato. Em um grande exercício de imaginação, o jornal apresenta o livro sonoro como "o livro do futuro", sendo impresso não mais em papel mas “em um cilindro de metal, e colocado em um pequeno autômato que pode ser tocado à vontade e que será lido a partir do lugar em que está colocado até o fim, a menos que seja interrompido" (THE BOOK..., 24 jun. 1885 , p. 4, tradução nossa $)^{5}$.

Nas possibilidades de leitura imaginadas pelo jornal, está a audioleitura fora do ambiente doméstico, em deslocamentos ou ao ar livre. Ao mesmo tempo, as reflexões sobre a máquina apontam problemas como distração das atividades cotidianas e influência da tecnologia em determinados elementos da leitura, como controle e velocidade, a entonação, a pronunciação, entre outros. A avaliação do jornal sobre o "livro do futuro" encontra nesse formato textual até mesmo relevância econômica para a Austrália. Afinal, o cobre, um dos principais insumos locais à época e "um dos metais mais sonoros", teria um novo uso ao substituir o papel e "ser o meio das máquinas de sussurro" (THE BOOK..., 24 jun. 1885, p. 4, tradução nossa) ${ }^{6}$. Porém, sabemos, o papel nunca foi ameaçado pelo cobre.

Na própria fonografia, logo os cilindros foram trocados pelos diversos modelos de discos de vinil, com maior capacidade de armazenamento, levando a possibilidade de gravação de obras mais longas e reduzindo a necessidade de cortes drásticos no texto a ser sonorizado. Além da facilidade de estocagem.

De acordo com Jesper Olsson, em The Audiographic Impulse - Doing literature with the tape recorder (OLSSON, 2011), foi da fita magnética o impacto mais profundo no que ele denomina recorded literature, possibilitando novas formas de trabalhos e composições - inclusive pela maior facilidade de acesso e uso da tecnologia de gravação por amadores - e afetando as conceituações de tempo, memória, identidade,

\footnotetext{
${ }^{5} \mathrm{O}$ texto em língua estrangeira é: “[...], the book of the future is to be printed on a metal cylinder, and placed in a small automaton which can be wound up at pleasure, and which will read from the place at which it is set right on to the end, unless it is stopped." (THE BOOK..., 24 jun. 1885, p. 4).

${ }^{6} \mathrm{O}$ texto em língua estrangeira: "[...] But as copper is the most sonorous of all the metals it must be the medium of the whispering machines" (THE BOOK..., 24 jun. 1885, p. 4).
} 
voz e narrativa. Ademais, segundo ele (2011), questões de representação (simbólico/real), distribuição e recepção da literatura também sofreram impacto.

Olsson (2011) destaca como primeiras consequências do uso das fitas a "objetificação" do som, isto é, esse poderia ser editado e manipulado, o que era mais complicado no emprego do fonógrafo. Um método de manipulação do som nas práticas artísticas com a fita magnética é o "cut-up", que consiste em cortar, recombinar, justapor trechos das fitas originais para produzir novos textos, distorcendo formas privilegiadas de narrativa, na visão de Olsson.

Ainda assim, a fita não era considerada um meio realmente viável para o mercado literário, aponta Olsson, em função do domínio do livro. Escritores como o americano David Antin, citado pelo pesquisador, viam a fonografia como modo de armazenamento de seus textos falados para posterior revisão e adaptação ao impresso, ou seja, como parte do processo de composição (OLSSON, 2011).

No entanto, alguns artistas encontraram modos alternativos de incluir a tecnologia dentro dessa rede de distribuição, como lançamentos de obras com os formatos em papel e em som para que o leitor simultaneamente ouvisse o texto sonoro enquanto olhasse para a página. Tal prática engajaria o leitor de maneira diferente - pela demanda de mais funções motoras e atos perceptivos na recepção da obra - e daria controle maior ao autor sobre o texto com a sua própria interpretação na gravação (OLSSON, 2011).

$\mathrm{Na}$ arqueologia das tecnologias sonoras feita por Olsson (2011), apenas no final dos anos 60 e início dos 70 as obras literárias sonoras teriam lançamentos mais frequentes, o que se deve principalmente, nas palavras dele, à invenção da gravação em cassete, flexível e durável o suficiente para servir como meio de distribuição para editores, escritores e artistas. Nas décadas seguintes, nos Estados Unidos, a indústria dos audiolivros, com grandes e pequenas editoras, alcança seu boom, como afirma Platt (2012). O autor aponta como alguns dos fatores desse crescimento o advento do walkman, da Sony, e a prevalência dos tocadores de fita nos carros, facilitando a possibilidade da escuta individual e móvel.

O sucesso fez emergir críticas. Uma delas era que, em muitos casos, a capacidade de armazenamento das fitas levava a uma necessária redução das obras a serem gravadas, degradando a arte. Caso se optasse pela manutenção dos textos de maneira integral, era necessário colocá-los em diversas fitas cassete. Podemos ver, 
assim, que tais suportes (a fita e o reprodutor) implicavam determinadas operações para quem produzia os livros em áudio, para adequá-los ao formato, e comportamentos para os leitores, que necessitavam trocar de lado ou de fita para dar prosseguimento à narrativa.

Posteriormente, a tecnologia digital pôde, de certa maneira, contribuir para modificar tais práticas de leitura com o CD (compact disc) e, principalmente, a tecnologia MP3, formato de codificação que potencializou ainda mais a portabilidade dos registros sonoros por conta de sua compatibilidade com diversas plataformas, facilitando o compartilhamento, e sua forma específica de compressão de dados, reduzindo significativamente a necessidade de espaço físico para o armazenamento desses arquivos de áudio (STERNE, 2006).

No lado comercial, é possível identificar transformações em modelos de negócio na indústria dos audiolivros. O digital e a Internet criaram algumas das condições para melhor produção, distribuição e venda do audiolivro. Isso se reflete no destaque do comércio online como caminho preferencial e sustentável para as editoras de audiolivros, o que não significa falta de pontos de venda físicos, como livrarias e lojas de conveniências.

A mais recente aposta é o serviço de vendas e assinaturas de livros sonoros via aplicativos em que novas funcionalidades são exploradas, como a interação com as redes sociais e as possibilidades de armazenamento dos audiolivros lidos na nuvem e as respectivas "marcações textuais". No Brasil, desde 2014, os aplicativos da Ubook e Tocalivros estão disponíveis para dispositivos com $i O S$ e Android e se consolidaram como inovação mais recente no mercado nacional de audiolivros. A assinatura e a audioleitura pelo site e pelos apps dessas empresas seguem as tendências tecnológicas e os modelos de negócio na indústria de mídia de modo geral. Curiosamente, apesar dessas novidades e a expectativa de popularização do formato no país, não é possível dar um panorama sobre o mercado nacional de audiolivros, por falta de informações disponíveis sobre essa indústria.

\section{Considerações finais}

De todo modo, buscamos incluir o audiolivro dentro da longa história da leitura e apresentar, ainda que brevemente, a relação entre certas transformações nas tecnologias de gravação e reprodução do som e a constituição das obras sonoras e dos 
seus próprios leitores. Sem esquecer da importância do formato na garantia de acesso à literatura aos deficientes visuais desde o século XIX e, inversamente, da força e da legitimidade que a luta por acessibilidade garantiu aos livros gravados (RUBERY, 2016), um olhar sobre as variações (a partir da fonografia) e continuidades (com a história da leitura com o ouvido) na audioleitura, por meio de diversos momentos das gravações literárias dentro e fora do país, é que podemos vislumbrar a presença de uma literatura sonora com finalidades de entretenimento ao longo do tempo.

Ressalvamos, porém, que a intenção não foi resgatar toda a história do audiolivro, ainda que possamos expor as mudanças e aperfeiçoamentos tecnológicos que impactam na produção, na distribuição e no consumo desse meio literário. Há muito mais para ser investigado, numa perspectiva histórica, sobre essa mídia do que o que se pôde mostrar.

$\mathrm{Na}$ realidade, as informações colhidas nesta pesquisa documental permitem confrontar discursos e premissas sobre o audiolivro. $\mathrm{O}$ que se revelou foi a necessidade de se considerar o audiolivro como uma mídia em si, acessível a videntes e deficientes visuais - e não um subproduto do livro - e de se apreendê-lo como problema de pesquisa tendo em perspectiva as práticas oralizadas de leitura, a materialidade das tecnologias fonográficas e os mais diversos fatores culturais, sociais e econômicos. Enfim, as redes complexas que o configuram e o tornam produto de entretenimento.

Submetido em: 09.04.2016

Aceito em: 09.02.2017

\section{REFERÊNCIA BIBLIOGRÁFICA}

A VEZ do audiolivro. O Globo, Rio de Janeiro, 30 out. 2005. Revista O Globo. p. 41.

BARBOSA, Marialva. História da Comunicação no Brasil. Petrópolis: Vozes, 2013.

BARBOSA, Rafael de O. Um olhar sobre o audiolivro e as materialidades de seus suportes - da performance do corpo aos primeiros livros falados. In: ENCONTRO NACIONAL DE HISTÓRIA DA MÍDIA, 9., 2013, Ouro Preto. Anais. Porto Alegre: ALCAR, 2013, p.1-15. Disponível em: <http://www.ufrgs.br/alcar/encontros-nacionais1/encontros-nacionais/9o-encontro-2013/artigos/gt-historia-da-midia-sonora/um-olharsobre-o-audiolivro-e-as-materialidades-de-seus-suportes-2013-da-performance-docorpo-aos-primeiros-livros-falados>. Acesso em: 13 fev. 2017.

CAMLOT, Jason. The three-minute Victorian novel: remediating Dickens into sound. In: RUBERY, Matthew. Audiobooks, literature and sound studies. Routledge, 2011, 
p. $25-43$.

CAVALLO, Guglielmo. Entre o volumen e o codex: a leitura no mundo romano. In:

CAVAllO, Guglielmo; CHARTIER, Roger (Org.). História da leitura no mundo ocidental 1. São Paulo: Ática, 1998, p. 103-122.

COLEÇÃO traz à tona raridades do selo Festa. Folha de S. Paulo, São Paulo, 25 fev. 2005. Disponível em: <http://www1.folha.uol.com.br/fsp/ilustrad/fq2402200506.htm>. Acesso em: 24 jun. 2017.

DIÁRIO de um mago vira audiolivro de quatro horas. O Globo, Rio de Janeiro, p. 4, 18 jun. 1994.

DISCOS. Tabloide Digital - 35 anos de jornalismo sob a ótica de Aramis Millarch. S.d. Disponível em: <http://www.millarch.org/artigo/discos>. Acesso em: 13 fev. 2017.

ECHO PHONOGRAPHICO. São Paulo, ano I, n. 2, set. 1902. Disponível em: <http://200.144.6.120/uploads/acervo/periodicos/jornais/BR_APESP_IHGSP_EPHO_1 9020900.pdf>. Acesso em: 13 fev. 2017.

EDISON, Thomas A. The phonograph and its future. The North American Review, Cedar Falls, Iowa: University of Northern Iowa, v. 126, ed. 262, p. 527-537, May, 1878.

GRUPO DE TEATRO PAULO AUTRAN. O pequeno príncipe. Interpretação da obra de Antoine de Saint-Exupery. Música: Tom Jobim. [S. 1.]: Grupo de teatro Paulo Autran, [1950]. Disponível em: <https://www.youtube.com/watch?v=3QUoURQRwlw >. Acesso em: 13 fev. 2017.

HAMESSE, Jaqueline. O modelo escolástico da leitura. In: CAVALLO, Guglielmo; CHARTIER, Roger (Org.). História da Leitura no Mundo Ocidental 1. São Paulo: Ática, 1998, p. 123-145.

HAVE, Iben; PEDERSEN, Birgitte Stougaard. Digital Audiobooks: new media, users, and experiences. Nova Iorque: Routledge, 2016.

LIVROS falados chegam ao mercado. O Estado de S. Paulo, São Paulo, 2 jun. 1994, Caderno 2, p. D3.

MONOLOGOS e poesias. Echo Phonographico, São Paulo, ano I, n. 2, p. 1, set. 1902. Disponível em: <http://200.144.6.120/uploads/acervo/periodicos/jornais/BR_APESP_IHGSP_EPHO_1 9020900.pdf>. Acesso em: 13 fev. 2017.

O ECHO. [Anúncios de gramofones]. São Paulo, ano VIII, n. 75-76, maio 1908. Disponível em: <http://200.144.6.120/uploads/acervo/periodicos/revistas/RECO19080575.pdf>. Acesso em: 13 fev. 2017.

OLSSON, Jesper. The audiographic impulse - doing literature with the tape recorder. In: RUBERY, Matthew. Audiobooks, literature and sound studies. Nova Iorque: Routledge, 2011, p. 61-75.

O X da phonographia. Echo Phonographico. São Paulo, ano I, n. 12, p. 2, out. 1902. Disponível

em: 
<http://200.144.6.120/uploads/acervo/periodicos/jornais/BR_APESP_IHGSP_EPHO_1 9021000.pdf>. Acesso em: 13 fev. 2017.

PALMA, Daniela. Gramofones e gadgets para os lares do Brasil: consumo, cultura e tecnicismo na revista O Echo (1902-1918). Projeto História. Revista do Programa de Estudos Pós-Graduados de História. [S.1.], v. 43, abr. 2011. Disponível em: <http://revistas.pucsp.br/index.php/revph/article/view/7738>. Acesso em: 13 fev. 2017.

PARKES, Malcom. Ler, escrever, interpreter o texto. In: CAVALLO, Guglielmo; CHARTIER, Roger (Org.). História da Leitura no Mundo Ocidental 1. São Paulo: Ática, 1998, p. 103-121.

PESSOAS. O Globo. Rio de Janeiro, jun. 1994. Caderno Rio, p. 14.

PLATT, Daniel. An icon adrift: the modern library in the 1990s. In: GREENSPAN, Ezra; ROSE, Jonathan (Eds.). Book History - Volume 15. Baltimore, Maryland: The Johns Hopkins University Press, 2012, p. 183-209.

RUBERY, Matthew. Thomas Edison's Poetry Machine. 19: Interdisciplinary Studies in The Long Nineteeenth Century, v. 18, 2014.

2016.

The untold story of the talking books. Cambridge: Harvard University Press,

STERNE, Jonathan. The mp3 as cultural artifact. New media \& society, v. 8, n. 5, p. 825-842, 2006.

SVENBRO, Jesper. A grécia arcaia e clássica: a invenção da leitura silenciosa. In: CAVALLO, Guglielmo; CHARTIER, Roger (Org.). História da Leitura no Mundo

Ocidental 1. São Paulo: Ática, 1998, p. 41-69.

THE BOOK of the future: or whispering machines. A speculation. The Mercury. [S. 1.], p. 4, 24 jun. 1885. Disponível em: <http://trove.nla.gov.au/ndp/del/article/9106931〉. Acesso em: 13 fev. 2017.

ZÓZIMO. O Globo. Rio de Janeiro, p. 3, 30 set. 1993.

ZUMTHOR, Paul. A letra e a voz: a "literatura" medieval. São Paulo: Companhia das Letras, 1993. 